\title{
The Cognitive-Affective Crossfire: When Self-Consistency Confronts Self-Enhancement
}

\author{
William B. Swann, Jr., John J. Griffin, Jr., Steven C. Predmore, and \\ Bebe Gaines \\ University of Texas at Austin
}

\begin{abstract}
Self-consistency theory assumes that people want others to treat them in a predictable manner. Selfenhancement theory contends that people want others to treat them in a positive manner. We attempted to help reconcile the two theories by testing the hypothesis that people's cognitive responses conform to self-consistency theory and their affective responses conform to self-enhancement theory. We presented individuals who possessed either positive or negative self-concepts with either favorable or unfavorable social feedback. We then measured cognitive reactions to the feedback (e.g., perceived self-descriptiveness) and affective reactions to the feedback (e.g., mood states). Cognitive responses were primarily driven by the consistency of the feedback and affective responses were controlled by how enhancing it was. We propose that conceptualizing cognition and affect as partially independent mental systems helps resolve some long-standing paradoxes regarding people's responses to selfrelevant social feedback.
\end{abstract}

\begin{abstract}
When we undertake to cure a patient, to free him from the symptoms of his malady, he confronts us with a vigorous, tenacious resistance that lasts during the whole time of the treatment. This is so peculiar a fact that we cannot expect much credence for it. . . . Just consider, this patient suffers from his symptoms and causes those about him to suffer with him . . . and yet he struggles, in the very interests of the malady, against one who would help him. How improbable this assertion must sound! (Freud, 1921, p. 248)
\end{abstract}

Improbable perhaps, yet Freud's assertion has fared well over the years. Self-consistency theorists, for example, contend that much like Freud's patients, people with negative self-concepts undermine opportunities to better themselves by engaging in cognitive and behavioral activities that perpetuate their selfviews. Yet, as Freud feared, such contentions have raised a fair number of eyebrows. Self-enhancement theorists, for example, have rejected self-consistency theory by arguing that in fact people with negative self-concepts are highly motivated to improve their self-views. This raises an important question: Does selfconsistency or self-enhancement theory offer a more compelling characterization of human nature?

The research and preparation of this article were supported by National Institute of Mental Health (NIMH) Grant MH-37598 and NIMH Research Scientist Development Award MH-00498 to William B. Swann, Jr, who was a Visiting Fellow at Princeton University during the preparation of the article.

We are grateful to Solomon Asch, Joel Cooper, John Darley, Scott Dickman, Daniel Gilbert, Edward Jones, and Nancy Hazen for their comments on early versions of the manuscript, to Sally Gaines for her help during the empirical phases of the investigation, and to John Loehlin for statistical advice.

Correspondence concerning this article should be addressed to William B. Swann, Jr., Department of Psychology, University of Texas, Austin, Texas 78712 .

\section{Self-Consistency Versus Self-Enhancement}

Self-consistency theory can be traced to the writings of Prescott Lecky (1945). His central assumption was that self-conceptions are critical for survival because they enable people to predict and control the nature of social reality (e.g., Epstein, 1973; Mead, 1934). People are therefore motivated to preserve their self-views, which they do by thinking and behaving in ways that perpetuate their conceptions of self.

Since Lecky's (1945) initial statement, several theorists have extended his formulation by identifying several specific cognitive and behavioral strategies through which people stabilize their self-views (e.g., Secord \& Backman, 1965; Swann, 1983). Furthermore, some (e.g., Epstein, 1983; Swann, 1983) have suggested that these activities are mediated by a highly general, cognitively based preference for stimuli that are predictable, familiar, stable, and uncertainty reducing. From this vantage point, people strive to acquire information that confirms their selfconceptions because their thought processes are structured so that confirmatory information seems especially trustworthy, diagnostic, and accurate.

Self-enhancement theory is based loosely on various personality theories (e.g., Horney, 1937; Rogers, 1961) and learning theory. Its central assumption is that people are motivated to increase their feelings of personal worth (e.g., Epstein, 1973; Tesser, 1985). In addition, self-enhancement theory (at least in its most logically consistent and popular form) assumes that because people with negative self-concepts lack self-esteem more than their counterparts, they will compensate for their lack of self-esteem by trying to enhance their self-views more than will their high self-esteem counterparts (e.g., Jones, 1973).

Both theoretical formulations predict that people with positive self-views work to maintain such views, albeit for different reasons. However, the two theories make competing predictions regarding people with negative self-views. That is, self-consistency theorists assume that individuals with negative self- 
concepts prefer negative feedback because it is predictable; selfenhancement theorists assume that such individuals prefer positive feedback because they want to think well of themselves.

Given that self-consistency and self-enhancement theory make very different predictions regarding responses of individuals who possess negative self-views, it appears that one theory could be discounted by simply examining the relevant responses of such individuals. This is not so. Several decades of research have produced mixed results, with some studies favoring self-consistency theory and others favoring self-enhancement theory (for reviews, see Jones, 1973; Shrauger, 1975; Swann, 1985).

Shrauger (1975) attempted to bring order to this confusing state of affairs by suggesting that some dependent variables tended to produce consistency effects and others tended to produce enhancement effects. In particular, measures of certain cognitive processes (e.g., recall, perceptions of the self-descriptiveness of feedback) ${ }^{1}$ seemed to support self-consistency theory. In contrast, measures that had a more affective flavor (e.g., pleasure or disappointment with feedback) seemed to support the self-enhancement position. An intriguing implication of Shrauger's proposal was that people with negative self-concepts would have rather ambivalent reactions to unfavorable feedback. Although such individuals might value such feedback on a cognitive level, they would also find it affectively abhorrent.

Although Shrauger's (1975) hypothesis was reasonably consistent with the existing data, workers in the area were slow to accept it. One problem was that Shrauger provided little theoretical justification for his notion that cognitive and affective responses were independent. In addition, he was unable to marshal direct empirical evidence for his hypothesis. We shall focus on these two shortcomings in this article. We will deal first with the empirical issues and leave the conceptual issues for the General Discussion.

\section{Evidence for the Cognitive-Affective Independence Hypothesis}

The major problem with the evidence Shrauger (1975) cited in support of his cognitive-affective independence hypothesis was that researchers had examined either cognitive or affective reactions; no one had examined both types of reactions in the context of a single study. This introduced the possibility that procedural differences other than the nature of the dependent variable could have accounted for the conflicting results of those who examined cognitive versus affective reactions.

Since Shrauger's review, two published investigations have attempted to test his hypothesis directly. ${ }^{2}$ Neither has offered strong support for his position. McFarlin and Blascovich (1981) tapped cognitive responses by asking people (a) to indicate their ability to perform a task and (b) to predict how well they would perform. The measure of affect was problematic, however. Instead of providing participants with feedback and measuring their affective reactions, the researchers asked them to indicate their preferences regarding future performances.

Given the absence of a direct measure of affective reactions to feedback, the McFarland and Blascovitch (1981) study is at best tangentially relevant to the hypothesis that people with negative self-views value unfavorable feedback on a cognitive level yet find it affectively abhorrent. Therefore, it may not be telling that some of their results contradicted Shrauger's hypothesis. Most important, contrary to the cognitive-affective independence notion, the affective measure was as closely associated with one of the measures of cognition $(r=.62)$ as the two measures of cognition were to one another $(r=.67)$.

The results of a field investigation by Moreland and Sweeney (1984) are potentially more relevant to Shrauger's hypothesis. These investigators assessed the relation between scores on a midterm exam and students' subsequent affective states and cognitive appraisals of the exam. The findings were complex, but it is fairly clear that both the cognitive and affective responses supported the self-enhancement position. Contrary to Shrauger's hypothesis and consistency theory, participants with low self-esteem generally regarded positive feedback as more self-descriptive than negative feedback.

Nevertheless, there is a good reason why Moreland and Sweeney's (1984) measures of cognitive reactions may have failed to support self-consistency theory. Consider that most college students possess relatively high self-esteem. Given this, Moreland and Sweeney's procedure of identifying low-self-esteem individuals by performing a median split may have classified people who were in reality high in self-esteem as low in selfesteem. Such misclassified high-self-esteem individuals would reject the negative feedback as being nondescriptive of self: not in the service of self-enhancement strivings, as the authors concluded, but in the service of self-consistency tendencies. For this reason, the pattern of cognitive responses that Moreland and Sweeney interpreted as supportive of self-enhancement theory may have in reality supported self-consistency theory.

In short, more than a decade has passed since Shrauger (1975) presented his important hypothesis, and the verdict is still out. What is needed is a study in which (a) people who possess negative or positive self-views receive feedback that is clearly consistent or inconsistent with their self views and (b) cognitive and affective reactions are measured by instruments capable of discriminating the two. Toward this end, we recruited individuals who scored in the upper or lower 20th percentile of a large sample on a measure of self-esteem. We presented favorable feedback to some individuals and unfavorable feedback to others. We then measured, in counterbalanced order, cognitive and affective reactions to the feedback.

Cognitive reactions included participant's perceptions of the accuracy of the feedback, competence of the evaluator, diagnosticity of the evaluation technique, and attributions regarding the cause of the feedback. We used a mood measure to tap affect because we believed that such a measure would provide us with a relatively pure index of affect. We also measured attraction to

\footnotetext{
${ }^{1}$ After Shrauger (1975), we use the term cognitive processes in a limited sense to refer to the relatively analytical, controlled processes that are presumably indexed by ratings of self-descriptiveness. As a result, when we use the term cognitive-affective crossfire, we are referring to a conflict between the products of these analytical processes and the affective system rather than to a conflict between the entire cognitive system and the entire affective system.

${ }^{2}$ A field investigation $(N=22)$ by Losco-Szpiler and Epstein (1978) also addressed this issue, but a detailed analysis of the results was unavailable as of this writing.
} 
the rater so that we would be able to compare our findings to those of earlier investigators who assessed this variable. As have previous workers (e.g., Shrauger, 1975), we believed that this measure might tap both cognitive and affective reactions because attraction to a rater might be influenced by one's perception of that rater's credibility as well as the mood induced by that rater.

Our major prediction was that cognitive reactions to the feedback would be relatively independent of affective reactions. Specifically, we anticipated that cognitive reactions would be based on the degree to which the feedback confirmed participant's self-views, with confirmatory feedback regarded as more accurate, diagnostic, and so on. In contrast, we expected that affective reactions would be based on the favorability of the feedback, with favorable feedback producing more positive mood states than unfavorable feedback.

\section{Method \\ Participants and Measure of Self-Concept}

Participants were 48 male and 58 female undergraduates who took part in the investigation for credit in their introductory psychology course. Five participants were deleted because they were suspicious of the experimental procedure.

Participants were drawn from a large sample of students who completed Helmreich, Spence, and Stapp's (1974) Texas Social Behavior Inventory (TSBI) during a pretest session at the beginning of the semester. This scale emphasizes social self-esteem (e.g., l have no doubts about my social competence," "I am not likely to speak to people until they speak to me." Scores on the TSBI could range from 16 to 80; the actual range was 25 to 80 . We classified individuals who scored below the 20th percentile (5I) as negative-self-concept individuals and those who scored above the 80 th (66) percentile as positive-self-concept individuals. Experimenters remained unaware of participants' TSBI scores throughout the experimental procedure. We also measured the certainty of participant's self-views. This variable had no effects on the dependent variables and will not be discussed further.

\section{Procedure}

Cover story and speech. A female experimenter introduced the experiment as an investigation of the accuracy of first impressions formed on the basis of nonverbal information only. She explained that two people would be involved in the experiment, the participant and an evaluator. The first step would be for the participant to deliver a speech. The evaluator would watch the participant deliver the speech through a soundproof, one-way mirror, allegedly to prevent the evaluation from being influenced by what the participant said. The evaluator would then assess the participant. Shortly thereafter, the participant would examine the evaluator's assessment and judge its accuracy. Comments made by participants during debriefing revealed that they found this cover story entirely plausible.

The speech consisted of several unremarkable excerpts from Desmond Morris's novel The Naked Ape. After giving the speech, the participant waited for $5 \mathrm{~min}$ while the evaluator ostensibly prepared his or her evaluation (evaluators were always alleged to have the same sex as the participant). The experimenter then entered with a handwritten evaluation that had been prepared in advance. In the favorable feedback condition, the feedback asserted that the participant was socially skilled:

From the way he (she) looked reading this speech this person seems socially self-confident. I'd say he (she) probably feels comfortable and at ease around other people he (she) doesn't know very well.
He (she) seems to have little doubt of his (her) social competence. That's about all I could tell about him (her).

In the unfavorable feedback condition, the feedback was simply the negation of that used in the favorable feedback condition:

From the way he (she) looked reading this speech this person doesn't seem real socially self-confident. I'd say he (she) probably feels somewhat uncomfortable and anxious around other people he (she) doesn't know too well. He (she) seems to have some doubts about his (her) social competence. That's about all I could tell about him (her).

Cognitive and affective reactions to the feedback. Immediately after reading the feedback participants completed two series of questionnaires in counterbalanced order. One set of questionnaires tapped their cognitive reactions to the feedback and another assessed their affective reactions to the feedback. Three additional items measured attraction to the evaluator.

We assessed four distinct cognitive reactions. Five items indexed perceived accuracy of the feedback, five items assessed perceived competence of the evaluator, three items tapped perceived diagnosticity of the rating technique, and two items measured participant's attributions regarding the feedback.

We assessed affective reactions with a measure of mood, Zuckerman and Lubin's (1965) Multiple Affect Adjective Checklist (MAACL). This instrument is designed to measure depression, anxiety and hostility.

After participants completed all measures of cognition and affect, they were thoroughly debriefed, thanked, and dismissed.

Item analysis. Items were deleted from our measures if including them in a given scale diminished the internal consistency of that scale. According to this criterion, we deleted single items from the perceived competence, perceived diagnosticity, and liking for the evaluator scales. The reliability analyses reported in the Appendix indicate that all of our scales displayed high levels of internal consistency. The precise wording of all measures included in the analyses can also be found in the Appendix.

Observer ratings. To obtain a rough index of the veridicality of our participants' self-ratings, we had two observers watch participants give their speech and rate them on the following bipolar trait scales: unsociable-sociable, socially confident-unconfident, socially awkward-poised, shy-outgoing, self doubting-self assured, socially competent-incompetent, cold-warm, nervous-at ease. Observers also attempted to guess whether participants had high or low self-esteem.

\section{Results and Discussion}

We examined the impact of the self-concept, feedback, and order of presentation variables on participants' cognitive and affective reactions. We then assessed covariation between the cognitive and affective measures by submitting them to a factor analysis. Finally, we examined the impact of self-concept on the ratings of observers. The effects of sex of participant are not discussed as this variable did not qualify any of the findings reported here.

\section{Impact of Feedback, Self-Concept, and Order on Cognitive Reactions}

All measures of cognitive reactions were entered into 2 (feedback: favorable, unfavorable) $\times 2$ (self-concept: positive, negative) $\times 2$ (order: cognitive first, affective first) least squares analyses of variance (ANOVAS). Our primary prediction was that there would be an interaction between self-concept and feed- 
Table 1

Cognitive Reaction as a Function of Self-Esteem and Feedback

\begin{tabular}{|c|c|c|c|c|}
\hline \multirow[b]{2}{*}{$\begin{array}{l}\text { Cognitive } \\
\text { measure }\end{array}$} & \multicolumn{2}{|c|}{ Positive self-concept } & \multicolumn{2}{|c|}{ Negative self-concept } \\
\hline & $\begin{array}{c}\text { Favorable } \\
\text { feedback } \\
(n=22)\end{array}$ & $\begin{array}{c}\text { Unfavorable } \\
\text { feedback } \\
(n=18)\end{array}$ & $\begin{array}{c}\text { Favorable } \\
\text { feedback } \\
(n=26)\end{array}$ & $\begin{array}{c}\text { Unfavorable } \\
\text { feedback } \\
(n=32)\end{array}$ \\
\hline Accuracy & 32.45 & 10.50 & 20.62 & 29.22 \\
\hline Competence & 26.29 & 12.11 & 18.19 & 22.47 \\
\hline \multicolumn{5}{|l|}{ Evaluation of } \\
\hline technique & 13.71 & 8.22 & 10.92 & 12.15 \\
\hline Self-attribution & 6.86 & 3.39 & 6.12 & 6.63 \\
\hline Other-attribution & 4.91 & 6.06 & 6.13 & 4.50 \\
\hline
\end{tabular}

Note. The higher the mean, the greater the perceived accuracy of the feedback (range $=5-45$ ), the greater the perceived competence of the rater (range $=4-36$ ), the more diagnostic the technique (range $=2-18$ ), and the greater the attribution to self (range $=1-9$ ) or other (range = $1-9)$.

back, such that those with positive self-concepts would regard favorable feedback as especially self-descriptive (i.e., accurate, diagnostic, delivered by a competent rater, reflective of self) and those with negative self-concepts would regard unfavorable feedback as especially self-descriptive.

The means displayed in Table 1 support our predictions. The Self-Concept $\times$ Feedback interaction was reliable for all five cognitive measures, including accuracy, $F(1,90)=75.28, p<$ .001 , competence of the evaluator, $F(1,89)=55.36, p<.001$, diagnosticity of the evaluation technique, $F(1,90)=15.33, p<$ .001 , self-attribution, $F(1,90)=20.66, p<.001$, and other attribution, $F(1,90)=14.85, p<.001 .^{3}$

Simple effects analyses revealed that positive-self-concept individuals who received favorable feedback regarded it as more accurate, $F(1,39)=122.60, p<.001$, the rater as more competent, $F(1,38)=93.77, p<.001$, and the technique as more diagnostic, $F(1,38)=21.56, p<.001$. These individuals were also inclined to attribute the favorable feedback to themselves, $F(1,39)=21.56, p<.001$, and not to characteristics of the evaluator, $F(1,39)=5.48, p<.03$. Negative-self-concept individuals displayed precisely the opposite tendency. That is, negative-self-concept individuals who received unfavorable feedback regarded it as particularly accurate, $F(1,56)=12.77, p<$ .001 , and the evaluator as particularly competent, $F(1,56)=$ $6.26, p<.02$, and they were not inclined to attribute the feedback to characteristics of the evaluator, $F(1,56)=14.46, p<$ .001 . Relative to positive-self-concept individuals, these individuals also displayed nonreliable tendencies to regard the technique as more diagnostic and to attribute the feedback to themselves.

These data support the notion that people's cognitive reactions to feedback are driven by a concern with the consistency of the feedback with their self-conceptions. Closer examination indicated that cognitive reactions were also influenced by the sheer positivity of the feedback. That is, ignoring the self-concept variable, there was an overall tendency for participants to believe that the favorable feedback was more accurate, diagnostic, and so forth, than the unfavorable feedback. The main effect of feedback was reliable for all the measures save the measure of other attribution: accuracy, $F(1,90)=17.85, p<.001$, competence of the evaluator, $F(1,89)=16.50, p<.001$, diagnosticity of the evaluation technique, $F(1,90)=7.15, p<.001$, and self-attribution, $F(1,90)=11.48, p<.001$.

To assess the relative importance of the consistency and favorability of the feedback, we compared the percentage of variance accounted for by the Self-Concept $\times$ Feedback interaction versus the main effect of feedback. The interaction effect accounted for $88 \%, 85 \%, 76 \%, 56 \%$, and $74 \%$ of the systematic variance on the measures of accuracy, competence, diagnosticity, self-attribution, and evaluator attribution, respectively. The feedback effect accounted for only $5 \%, 10 \%, 18 \%, 18 \%$, and $10 \%$ of the systematic variance on these same measures. Of course, one must be careful in generalizing the results of this analysis, because characteristics of our experiment or subject population may have influenced the outcome.

Yet if cognitive responses are only sensitive to the consistency of the feedback, why should there have been any main effect of feedback at all? One possibility is that the self-views of positive as compared to negative self-concept individuals were more closely matched to the consistent feedback. That is, despite the fact that our negative-self-concept participants scored in the lower $20 \%$ of our pretest sample, their average score was 46 : just 2 points below the theoretical midpoint of the scale (range = 16-80). The self-views of negative-self-concept participants were therefore negative in a relative sense only. In contrast, the average score of our positive-self-concept individuals was 70 . Clearly, the self-views of these individuals were positive in an absolute as well as in a relative sense.

There were no main or interactive effects of the order variable on any of the cognitive measures.

\section{Affective Reactions to the Feedback}

All measures of affective reactions were entered into 2 (feedback: favorable, unfavorable) $\times 2$ (self-concept: positive, negative) $\times 2$ (order: cognitive first, affective first) least squares ANOVAS. Our major prediction was that positive- and negativeself-concept individuals alike would feel better after receiving favorable feedback as compared to unfavorable feedback. This was the case. The data in Table 2 indicate that participants who received unfavorable as compared to favorable feedback were more depressed, $F(1,92)=15.41, p<.001$, hostile, $F(1,92)=$ $8.81, p<.004$, anxious, $F(1,92)=11.97, p<.001$, and experienced less negative affect overall, $F(1,92)=15.92, p<.001$ (the last index was a composite measure comprised of the depression, hostility, and anxiety scores). Participants were also more attracted to the evaluator in the favorable feedback condition, $F(1,86)=43.86, p<.001$.

We also expected that the consistency of the feedback would not influence affective reactions. The measures of mood supported this prediction. That is, none of the mood measures showed an interaction between self-concept and feedback, all $F s n s$. There was, however, a reliable Self-Concept $\times$ Feedback interaction on the attraction variable, $F(1,86)=7.19, p<.01$.

\footnotetext{
${ }^{3}$ The degrees of freedom for different dependent measures vary slightly because participants occasionally failed to complete measures.
} 
Table 2

Affective Reaction as a Function of Self-Esteem and Feedback

\begin{tabular}{|c|c|c|c|c|}
\hline \multirow[b]{2}{*}{$\begin{array}{l}\text { Affective } \\
\text { measure }\end{array}$} & \multicolumn{2}{|c|}{ Positive self-concept } & \multicolumn{2}{|c|}{ Negative self-concept } \\
\hline & $\begin{array}{c}\text { Favorable } \\
\text { feedback } \\
(n=21)\end{array}$ & $\begin{array}{c}\text { Unfavorable } \\
\text { feedback } \\
(n=19)\end{array}$ & $\begin{array}{c}\text { Favorable } \\
\text { feedback } \\
(n=26)\end{array}$ & $\begin{array}{l}\text { Unfavorable } \\
\text { feedback } \\
(n=33)\end{array}$ \\
\hline \multicolumn{5}{|c|}{ Overall negative } \\
\hline Depression & 29.41 & 24.21 & $\begin{array}{l}39.80 \\
26.85\end{array}$ & 22.70 \\
\hline Hostility & 21.59 & 17.37 & 19.92 & 18.94 \\
\hline Anxiety & 16.09 & 13.47 & 13.08 & 10.33 \\
\hline Attraction & 12.90 & 7.00 & 12.92 & 10.07 \\
\hline
\end{tabular}

Note. The higher the mean, the more positive the overall affective state ( range $=0-89$ ), the less depressed (range $=0-40$ ), the less hostile (range $=0-28$ ), the less anxious (range $=0-21$ ) and the greater the attraction to the rater.

Although everyone preferred favorable evaluators to unfavorable ones, this tendency was stronger among positive-selfconcept individuals, $F(1,38)=41.5, p<.001$, as compared with negative-self-concept individuals, $F(1,53)=10.93, p<$ .001 . Even so, the interaction effect on the attraction variable accounted for only $9 \%$ of the systematic variance; in contrast, the feedback effect accounted for $67 \%$ of the systematic variance.

The analyses also revealed that participants' emotional reactions to the feedback were more polarized when the measures of affect were collected before rather than after the measures of cognition. The means in Table 3 indicate that order interacted with feedback on the measure of depression, $F(1,92)=4.90$, $p<.03$, hostility, $F(1,92)=4.68, p<.04$, overall negative affect, $F(1,92)=4.90, p<.03$, and attraction to the evaluator, $F(1,86)=10.68, p<.002$. A similar but nonreliable pattern characterized the measure of anxiety $(p<.16)$.

Simple effects analyses revealed that when the affective measures occurred first, participants displayed a clear preference for the favorable evaluation and evaluator on all five measures of affect (all $p s<.001$ ). In contrast, when the affective measures were collected second, the preference for favorable feedback

Table 3

Affective Reaction as a Function of Order and Feedback

\begin{tabular}{lccccc}
\hline & \multicolumn{2}{c}{ Affective first } & & \multicolumn{2}{c}{ Cognitive first } \\
\cline { 2 - 3 } \cline { 5 - 6 } & $\begin{array}{c}\text { Favorable } \\
\text { feedback } \\
\text { Affective measure }\end{array}$ & $\begin{array}{c}\text { Unfavorable } \\
(n=19)\end{array}$ & $\begin{array}{c}\text { Feedback } \\
(n=31)\end{array}$ & $\begin{array}{c}\text { Feedback } \\
\text { forable } \\
(n=29)\end{array}$ & $\begin{array}{c}\text { Unfavorable } \\
\text { feedback } \\
(n=21)\end{array}$ \\
\hline Negative affect & 65.16 & 50.48 & & 61.86 & 56.85 \\
Depression & 29.05 & 22.10 & 27.34 & 24.95 \\
Hostility & 21.16 & 17.42 & 20.38 & 19.76 \\
Anxiety & 14.95 & 10.97 & 14.14 & 12.24 \\
Attraction & 13.68 & 8.10 & 12.39 & 10.20 \\
\hline
\end{tabular}

Note. The higher the mean, the more positive the overall affective state, the less depressed, the less hostile, the less anxious, and the greater the attraction to the rater. was consistently weaker. In fact, this preference was only reliable in the case of the measure of attraction $(p<.01)$.

Why did affective responses to the feedback vanish when they were measured after the measures of cognition? One possibility is that the simple passage of time diminished affective responses. Alternatively, the act of completing the cognitive measures may have been critical. Although this is plausible, it was not that completing the cognitive measures focused attention on the discrepancy between affect and cognition, because even positive-self-concept individuals (for whom there was no such discrepancy) displayed weaker affective reactions to the feedback after completing the cognitive measures.

\section{Covariation Between the Measures of Cognition and Affect}

To determine if the measures of cognition and affect were orthogonal, we entered the measures of cognitive and affective reactions into a principle components factor analysis with oblique rotation (Nie, Hull, Jenkins, Steinbrenner, \& Bent, 1975). Two factors emerged from the initial oblique solution. The first factor accounted for $47 \%$ of the variance and had an eigenvalue of 4.24 . The second factor accounted for $24.4 \%$ of the variance and had an eigenvalue of 2.19 . The eigenvalues for all other factors were less than 1.

The loadings for the first two factors after rotation can be seen in Table 4. All of the cognitive measures loaded heavily on the first factor only, and all of the mood measures loaded heavily on the second factor only. The sole measure that loaded on both factors was the index of attraction to the evaluator. It is therefore not surprising that the correlation between the first and second factors was a modest -.24 . This evidence of cognitive-affective independence is especially striking when one considers that the cognitive and affective measures shared some method variance because we used self-reports to tap affective states.

In summary, the factor analysis indicated that (a) the cognitive measures were closely related to one another but were relatively independent of the affective measures, (b) the affective measures were closely related to one another but were relatively

Table 4

Oblique Factor Pattern Matrix After Rotation

With Kaiser Normalization

\begin{tabular}{lrr}
\multicolumn{1}{c}{ Measure } & Factor 1 & Factor 2 \\
\hline Cognitive measures & & \\
Perceived accuracy of the feedback & .99 & .05 \\
Perceived competence of evaluator & .94 & -.06 \\
Perceived diagnosticity of the technique & .71 & .03 \\
Attribution to self & .70 & -.01 \\
Attribution to other & .65 & .08 \\
Affective measures & & \\
Depression & .01 & .93 \\
Hostility & -.12 & .74 \\
Anxiety & .13 & .82 \\
Attraction to evaluator & .49 & -.34 \\
\hline
\end{tabular}

Note. $\Delta=0$ 
independent of the cognitive measures, and (c) the attraction measure was a hybrid measure that was related to both the cognitive and affective measures.

\section{Observer Ratings}

Observers were able to discriminate positive-self-concept individuals from their counterparts. One way ANOVAS revealed that observers rated positive-self-concept participants as more sociable and self-confident than negative-self-concept individuals, $F(1,92)=7.01, p<.01, M \mathrm{~s}=95.9$ and 85.1 , respectively. Observers were also able to guess whether participants were high or low in self-esteem at an above-chance level, $F(1,92)=$ $5.66, p<.02$.

\section{General Discussion}

Our findings suggest that both self-consistency and self-enhancement theory offer valuable insights into people's reactions to social feedback. For example, as self-consistency theory suggests, participants with negative self-concepts indicated that unfavorable feedback was more self-descriptive than favorable feedback. As self-enhancement theory suggests, even though those with negative self-concepts regarded unfavorable feedback to be quite accurate and self-descriptive, they were more depressed, anxious, and hostile after they received it. Our data therefore provide strong support for Shrauger's (1975) hypothesis that cognitive reactions to social feedback conform to selfconsistency theory and affective reactions conform to self-enhancement theory.

Even so, our data raise questions regarding the assumptions underlying both self-consistency and self-enhancement theory. One relatively minor question, which is specific to self-enhancement theory, concerns the fact that the affective reactions of participants with positive and negative self-conceptions did not differ. This is inconsistent with the strong form of self-enhancement theory, which stipulates that relative to individuals with positive self-concepts, those with negative self-concepts should be more pleased by positive feedback and more displeased by negative feedback. Our data, together with the fact that there is little definitive support for the strong version (see Shrauger, 1975), suggest that it may be time to opt for a weak form of selfenhancement theory in which people with positive self-views prefer favorable feedback just as much as those with negative self-views.

A more fundamental problem with both self-consistency and self-enhancement theory is raised by our evidence that cognitive and affective reactions seemed relatively independent. This finding is problematic for both theories because both subscribe to the assumption of psychological unity, which holds that a superordinate cognitive system oversees all mental activity and resolves inconsistencies between thoughts, feelings, and actions. Our findings clearly clash with the unity assumption in that our participant's cognitive and affective reactions seemed independent. That is, both the factor analysis and the fact that cognitive reactions were more likely to persist over time than affective reactions suggest that cognitive and affective responses are independent. More important, the overall pattern of data indicate that cognitive responses were based on the subjective veridical- ity of the stimuli, such as the extent to which the feedback was consistent with the person's self-views, and affective responses were based simply on whether or not the feedback was threatening.

One implication of our findings, then, is that both self-consistency and self-enhancement theorists should drop the unity assumption. Some have already begun to do this. Swann (1987), for example, has suggested that the self-verification formulation (a variant of self-consistency theory) applies to cognitive and behavioral responses but not affective responses. In light of the wide range of responses that fall into these response classes, it may be necessary for theorists to become even more specific regarding the type of responses covered by their theories.

Our evidence that cognitive and affective responses are independent raises questions concerning why this might be the case. Recent work by dual- and multiple-systems theorists (e.g., Epstein, 1983; Gazzaniga, 1985; Greenwald, 1982; Izard, 1984; Tomkins, 1981; Wilson, 1985; Zajonc, 1980) may be relevant here. This work suggests that the cognitive and affective systems are designed to perform very different tasks. The cognitive system is presumably designed to classify stimuli and analyze their logical properties and subjective veridicality. For example, when social feedback is received it is first classified (e.g., favorable or unfavorable to self). Then the feedback is compared to information about the self stored in memory. If the feedback concurs with the information in memory, it is accepted as selfdescriptive; if not, it is rejected.

Two characteristics of the decision process that the cognitive system uses are especially noteworthy. First, analysis of the subjective veridicality of stimuli is relatively time consuming because it entails searching memory and comparing the stimulus with stored information. Second, decisions reached by the cognitive system are only incidentally sensitive to the valence of feedback. That is, because the cognitive system is concerned with how incoming feedback compares with existing knowledge of self, the valence of the feedback matters only in that it determines whether it is classified as consistent or inconsistent with the self.

In contrast, the affective system enables the organism to respond quickly to events that pose an immediate threat to personal safety. This rather primitive system reacts on the basis of relatively gross discriminations (i.e., threatening vs. not threatening, favorable to self vs. unfavorable to self) and little or no analysis of the subjective veridicality of stimuli. This system, then, trades precision for speed. It may not perform highly sophisticated analyses of stimuli, but it reacts quickly.

The major difference between the cognitive and affective systems, then, is how they improve the organism's chances of survival. The cognitive system achieves this end through a systematic analysis of the subjective veridicality of stimuli; the affective system does so by quickly recognizing threats to safety and spurring the organism to action. To be sure, the distinction between the two systems is not clear-cut (e.g., Epstein, 1983). For example, affective responses are dependent on some rudimentary cognitive analyses of stimuli, enough to allow the organism to recognize the stimuli (e.g., Lazarus, 1984; see also discussions by Birnbaum, 1981; Mellers, 1981; Zajonc, 1980; 1984). In our opinion, however, the fact that some interaction may occur between the cognitive and affective systems does not dimin- 
ish the utility of conceptualizing them as relatively independent systems with distinct capabilities and agendas.

An important implication of the cognitive-affective independence notion, of course, is that it suggests the possibility that people may be caught in crossfires between the two. In our study, for example, participants with negative self-views who received unfavorable feedback found such feedback cognitively acceptable yet affectively abhorrent. This prompts one to ask how people escape from such crossfires.

One possibility is that the cognitive system resolves such crossfires by muting or transforming the affective response. Indeed, the structure of the cognitive and affective systems might favor such an outcome: Insofar as the affective system is adapted for rapid decision-making processes and the cognitive system is adapted for more reflective processes (e.g., Epstein, 1983; Zajonc, 1980), the cognitive system should become increasingly dominant over time.

Our findings offer some support for the notion that cognitive responses eventually encroach upon affective responses. That is, our participants' affective responses to feedback faded over time while their cognitive responses persisted. Other investigators have offered additional evidence of a tendency for cognitions to modify affective experiences. For example, recent evidence indicates that when people's behavioral predispositions toward some target person are based largely on affect (e.g., when they have just met a target), inducing them to think about that target can systematically alter their subsequent behavior toward him or her (e.g., Millar \& Tesser, 1986; Wilson, Dunn, Bybee, Hyman, \& Rotondo, 1984). Similarly, there is evidence that people "manage" their emotions by altering or juggling cognitions related to those emotions (e.g., Hochschild, 1983). For example, to cope with a drunk and unruly passenger, a flight attendant might transform his or her anger into sympathy by supposing that the passenger is grieving the death of a spouse. A somewhat similar strategy is used by cognitive therapists (e.g., Beck, 1967; Ellis, 1962) who often treat emotional disturbances by encouraging clients to develop interpretations of negative events that are highly adaptive.

From this perspective, the cognitive system is remarkably facile at fashioning ways of avoiding or eliminating cognitiveaffective crossfires. Note, however, that such improvisations are not universally effective. At times, the source of the affect may be so powerful that no amount of cognitive gymnastics can defy it. In some cases, this may be for the best, particularly when the ability of the cognitive system to mute affective states might encourage people to make behavioral choices that actually increase affective distress in the future. For example, to the extent that people with negative self-views convince themselves that unfavorable feedback is desirable because it is trustworthy and predictable, they may be tempted to seek out intimates who are apt to provide them with such feedback (e.g., Swann \& Fisher, 1986). These intimates may then supply them with unfavorable feedback that fuels future bouts of depression (e.g., Swann \& Predmore, 1985).

\section{Implications and Conclusions}

Much of the history of social and personality psychology can be understood as an unsuccessful quest for evidence of psycho- logical unity. Part of this history, which involves efforts to find unity in people's reactions to feedback, has been discussed in this report. But researchers interested in responses to feedback have not been the only ones to venture into their laboratories in search of unity and emerge with evidence of disunity. For example, disunity and lack of consistency has been a major theme in research on the relation of attitudes to behavior (e.g., Fazio \& Zanna, 1981; Wicker, 1969) and in treatments of the "trait-situation controversy" (e.g., Magnusson \& Endler, 1977). Similarly, research on emotion and misattribution of arousal has suggested that two separate psychological systems contribute to the experience of emotion, one that controls arousal and another that interprets arousal (e.g., Zillman, 1983). Furthermore, investigations of people's introspective powers have suggested that the psychological system that explains overt behavior has no access to the system that generates behavior (e.g., Nisbett \& Wilson, 1977; Wilson, 1985).

To be sure, the assumption of psychological unity is appealing in many ways. It is simple, elegant, and phenomenologically compelling. And it is pragmatic; were it not for the assumption of psychological unity, holding people responsible for their actions might be a rather awkward affair. Yet our data suggest that at least with respect to reactions to social feedback, people are not nearly as single minded as the unity assumption would have us believe.

\section{References}

Beck, A. T. (1967). Depression: Causes and treatment. Philadelphia: University of Pennsylvania Press.

Bimbaum, M. H. (1981). Thinking and feeling: A skeptical review. American Psychologist, 37, 99-101.

Ellis, A. (1962). Reason and emotion in psychoiherapy. New York: Lyle Stuart.

Epstein, S. (1973). The self-concept revisited: Or a theory of a theory. American Psychologist, 28, 404-416.

Epstein, S. (1983). The unconcious, the preconcious, and the self-concept. In J. Suls \& A. G. Greenwald (Eds.), Psychological perspectives on the self (Vol. 2, pp. 219-247). Hillsdale, NJ; Eribaum.

Fazio, R. H., \& Zanna, M. P. (1981). Direct experience and attitudebehavior consistency. In L. Berkowitz (Ed.), Advances in experimental social psychology (Vol. 14, pp. 162-202). New York: Academic Press.

Freud, S. (1921). A general introduction to psychoanalysis. New York: Boni \& Liverwright.

Gazzaniga, M. S. (1985). The social brain. New York: Basic Books.

Greenwald, A. G. (1982). Is anyone in charge? Personalysis versus the principle of personal unity. In J. Suls (Ed.), Psychological perspectives on the self(Vol. 1, 151-181). Hillsdale, NJ: Erlbaum.

Helmreich, R., Spence, J. T., \& Stapp, J. (1974). Short form of the Texas social behavior inventory, an objective measure of self-esteem. Bulletin of the Psychonomic Society, 4, 473-475.

Hochshild, A. (1983). The managed heart. Berkeley, CA: University of California Press.

Horney, K. (1937). The neurotic personality of our time. New York: Norton.

Izard, C. E. (1984). Emotion-cognition relationships and human development. In C. E. Izard, J. Kagan, \& R. B. Zajonc (Eds.), Emotions, cognition, and behavior (pp. 17-37). New York: Cambridge University Press.

Jones, S. C. (1973). Self and interpersonal evaluations: Esteem theories versus consistency theories. Psychological Bulletin, 79, 185-199. 
Lazarus, R. S. (1984). On the primacy of cognition. American Psychologist, 39, 124-129.

Lecky, P. (1945). Self-consistency: A theory of personality. New York: Island Press.

Losco-Szpiler, J. P., \& Epstein, S. (1978, April). Reactions to favorable and unfavorable evaluations in everyday life as a function of level of self-esteem. Paper presented at the meeting of the Eastern Psychological Association, Washington, DC.

Magnusson, D., \& Endler, N. S. (1977). Personality at the crossroads: Current issues in interactional psychology. Hillsdale, NJ: Erlbaum.

McFarlin, D. B., and Blascovich, J. (1981). Effects of self-esteem and performance on future affective preferences and cognitive expectations. Journal of Personality and Social Psychology, 40, 521-531.

Mead, G. H. (1934). Mind, self and society. Chicago: University of Chicago Press.

Mellers, B. A. (1981). Feeling more than thinking. American Psychologist, 36, 802-803.

Millar, M. G., \& Tesser, A. (1986). Effects of affective and cognitive focus on the attitude-behavior relation. Journal of Personality and Social Psychology, 51, 270-276.

Moreland, R. L., \& Sweeney, P. D. (1984). Self-expectancies and reactions to evaluations of personal performance. Journal of Personality, 52, 156-176.

Nie, N. H., Hull, C. H., Jenkins, J. G., Steinbrenner, K., \& Bent, D. H. (1975). Statistical package for the social sciences. New York: McGraw-Hill.

Nisbett, R. E., \& Wilson, T. D. (1977). Telling more than we can know: Verbal reports on mental processes. Psychological Review, 84, 231259.

Rogers, C. R. (1961). On becoming a person: A therapists' view of psychotherapy. Boston: Houghton Mifflin.

Secord, P. F., \& Backman, C. W. (1965). An interpersonal approach to personality. In B. Maher (Ed.), Progress in experimental personality research (Vol. 2, pp. 91-125) New York: Academic Press.

Shrauger, J. S. (1975). Responses to evaluation as a function of initial self-perceptions. Psychological Bulletin, 82, 581-596.

Swann, W. B., Jr. (1983). Self-verification: Bringing social reality into harmony with the self. In J. Suls \& A. G. Greenwald (Eds.), Social psychological perspectives on the self (Vol. 2, pp. 33-66). Hillsdale, NJ: Erlbaum.

Swann, W. B., Jr. (1985). The self as architect of social reality. In B. Schlenker (Ed.), The self and social life (pp. 100-125). New York: McGraw-Hill.

Swann, W. B., Jr. (1987). Identity negotiation: Where two roads meet. Unpublished manuscript, University of Texas at Austin.

Swann, W. B., Jr., \& Fisher, D. A. (1986). Mate selection and the selfconcept. Unpublished manuscript, University of Texas at Austin.

Swann, W. B., Jr., \& Predmore, S. C. (1985). Intimates as agents of social support: Sources of consolation or despair? Journal of Personality and Social Psychology, 49, 1609-1617.

Tesser, A. (1985, August). Toward a self-evaluation maintenance model of social behavior. Paper presented at the annual convention of the American Psychological Association, Los Angeles.

Tomkins, S. S. (1981). The quest for primary motives: Biography and autobiography of an idea. Journal of Personality and Social Psychology, 41, 306-329.

Wicker, A. W. (1969). Attitudes versus actions: The relationship of verbal and overt behavioral responses to attitude objects. Journal of Social Issues, 25, 41-78.

Wilson, T. D. (1985). Strangers to ourselves: The origins and accuracy of beliefs about one's own mental states. In J. H. Harvey \& G. Weary (Eds.), Attribution in contemporary psychology (pp. 9-36). New York: Academic Press.

Wilson, T. D., Dunn, D. S., Bybee, J. A., Hyman, D. B., \& Rotondo, J. A. (1984). Effects of analyzing reasons on attitude-behavior consistency. Journal of Personality and Social Psychology, 47, 5-16.

Zajonc, R. B. (1980). Feeling and thinking: Preferences need no inferences. American Psychologist, 35, 151-175.

Zajonc, R. B. (1984). On the primacy of affect. American Psychologist, 39, 117-123.

Zillman, D. (1983). Transfer of excitation in emotional behavior. In J. T. Cacioppo \& R. Petty (Eds.), Social psychophysiology: A sourcebook (pp. 215-240). New York: Guilford.

Zuckerman, M., \& Lubin, B. (1965). Manual for the multiple affect adjective checklist. San Diego, CA: Educational and Industrial Testing Service. 


\section{Appendix}

\section{Measures of Cognitive and Affective Reactions}

All responses were recorded on 9-point Likert scales that used the anchors listed after each item.

\section{Perceived Accuracy of the Feedback (Alpha $=.93$ )}

1. How accurate do you think this impression of you was? (extremely accurate-inaccurate)

2. How much could a stranger learn about you from reading this impression of you? (nothing at all-a great deal)

3. How much did you agree with this impression of you? (strongly agreed-strongly disagreed)

4. How well thought out do you think the impression of you was? (not well thought out-extremely well thought out)

5. How much did the other subject learn about you by watching you give the speech? (nothing at all-a great deal)

\section{Perceived Competence of Evaluator (Alpha $=.94)$}

Rate where you think the person who wrote the impression of you would fall on the following trait scales by circling a number.

1. judge other people's personalities (extremely unable-extremely able)

2. form accurate first impressions of others (same as 1)

3. read other people (same as 1)

4. understand what others are thinking and feeling (same as 1)
Evaluation of the Diagnosticity of the Nonverbal Technique in Forming Impressions (Alpha $=.86$ )

1. How much do you think people's nonverbal behavior generally reveals to others about their personalities? (nothing at all-a great deal)

2. How much do you think an observer can learn about another person just by watching (not hearing) that person give a speech? (same as 1)

\section{Attribution to Self and to Other}

1. To what extent do you think the impression formed of you today was a result of the behavior you displayed giving the speech? (Not at all a result of my behavior-totally a result of my behavior)

2. To what extent do you think the impression formed of you was not a result of your behavior, but a result of the other subject's personal way of judging others. (Not at all a result of his/her way of judging others-totally a result of his/her way of judging others)

\section{Attraction to the Evaluator (Alpha $=.91)$}

1. How much do you think you would like the person who wrote this impression of you? (would not like this person at all-would like this person a great deal)

2. Describe your general reaction to the person who wrote the impression of you. (extremely negative-extremely positive)

Received June 24, 1985

Revision received September 9, 1986 